\title{
Working Together: Communication Between Stakeholders During the Transition from Early Intervention to School for Children Who Are Deaf or Hard of Hearing
}

\author{
Deirdre Curle \\ Washington State Center for Childhood Deafness \& Hearing Loss \\ Janet Jamieson, Brenda T. Poon, \& Marla Buchanan \\ The University of British Columbia \\ Nancy Norman \\ The University of the Fraser Valley \& Kwantlen Polytechnic University \\ Anat Zaidman-Zait \\ Tel Aviv University
}

\begin{abstract}
The transition to school can be a complicated process for families of children with exceptionalities (Janus, Lefort, Cameron, \& Kopechanski, 2007). Little is known about the transition to school specifically for children who are deaf or hard of hearing $(\mathrm{D} / \mathrm{HH})$. The aim of this study was to examine the communication that occurred among early intervention (EI) providers, parents, and teachers before and during the child's first year of kindergarten. Thematic analysis was used to analyze six sets of parent interviews, pre- and post-transition, three interviews with EI providers, and three interviews with teachers of the deaf. Participants from each group described factors that facilitated or hindered the transition to school for D/HH children. Findings were interpreted through the framework of ecological systems theory, which indicate that high-intensity transition support and fluid communication facilitated the transition and fostered positive relationships among those involved in the child's transition to school.
\end{abstract}


The transition from early childhood settings to formal schooling is a major milestone in the lives of young children and their families. This transition is influenced not only by the child's readiness for school, but also by a combination of family, peer, school, and community contexts, and the relationships among these contexts (Rimm-Kaufmann \& Pianta, 2000). A successful transition involves communication among the individuals and agencies most closely involved with the child prior to and following school entry. In fact, best-practice recommendations for facilitating a smooth transition to school emphasize strategies for increasing communication between home, school, and early childhood settings (Pianta \& Kraft-Sayre, 2003).

\section{Background to the Study}

\section{Transition to School for Children with Exceptionalities}

While the transition to school is of particular importance for all children, families of children with exceptionalities often find it to be a difficult time (Janus, Lefort, Cameron, \& Kopechanski, 2007; Poon et al., 2016). Parents of children with special needs report more concerns about how their child will function in a new environment, compared to parents of typically developing children (McIntyre et al., 2010). At the same time, these families experience multiple changes during the transition, including not only new teachers and peers for the child, but also changes at a systemic level, with differences in service delivery and approach between family-centred early intervention (EI) and childcentred school systems (Hanson et al., 2000). Altogether, these changes require a greater degree of adjustment for families of children with special needs than occurs for families of typically developing children as the children enter the school system.

The transition for children with special needs requires ample time for planning to ensure that the necessary accommodations are in place for an appropriately challenging, yet supportive educational program (Briody \& Martone, 2010). Consequently, families of children with exceptionalities and their EI service providers are often more involved in the transition to school, compared to families and preschool teachers of typically developing children (Welchons \& McIntyre, 2015). However, in spite of the importance of relationships and communication between stakeholders involved in the transition to school for children with exceptionalities, little is known about the communication that occurs among parents, EI professionals, and teachers. This is particularly true in the situation of children who are deaf or hard of hearing $(\mathrm{D} / \mathrm{HH})$, about which very little has been documented regarding the communication that occurs among stakeholders during this important transition.

\section{Considerations for Children Who Are D/HH}

Researchers have consistently found that $\mathrm{D} / \mathrm{HH}$ children have demonstrated delayed language development and academic underachievement compared to hearing peers (Qi \& Mitchell, 2012; Spencer \& Marschark, 2009). Consequently, many D/HH children receive specialized educational services and support from the time the hearing loss is identified throughout their school years. Roughly $40 \%$ of $\mathrm{D} / \mathrm{HH}$ children have additional disabilities (Gallaudet Research Institute, 2013) and require services to address physical, 
behavioural, or medical needs. Thus, children who are $\mathrm{D} / \mathrm{HH}$ often need numerous accommodations and services to support their learning and engagement in school.

Parents, EI professionals, and school district personnel are the primary stakeholders who take part in the transition to school for young children with exceptionalities. Teachers of the deaf (TODs), in particular, are frequently involved in supporting the transition when the child is $\mathrm{D} / \mathrm{HH}$. Each of these groups of stakeholders and their respective roles in the transition to school is discussed below.

Parents of D/HH children. Parents often experience intense emotions upon learning that their baby has a hearing loss, including grief, fear, and uncertainty about the future (Jackson, Traub, \& Turnbull, 2008). Managing the needs of a child who is $\mathrm{D} / \mathrm{HH}$, such as amplification equipment and frequent medical appointments, can put considerable pressure on hearing families that may result in continuous stress (Kurtzer-White \& Luterman, 2003; Poon \& Zaidman-Zait, 2014). During the child's early years, a multitude of important decisions must be made, including those concerning amplification, communication modality, and educational placement (Decker, Vallatton, \& Johnson, 2012; Fitzpatrick, Jacques, \& Neuss, 2011; Zaidman-Zait \& Curle, 2016). Parents have reported needs for information, therapy services, and service coordination (Fitzpatrick, Angus, DurieuxSmith, Graham, \& Coyle, 2008). In addition, parents have reported that it is helpful to receive information and support from other parents, as well as from their service providers (Jackson et al., 2008). On the other hand, a lack of information, particularly during times of transition, has been reported to be frustrating for parents (Jamieson, Zaidman-Zait, \& Poon, 2011) and presents a barrier to a smooth transition (Poon et al., 2016). Thus, it is reasonable to assume that parents benefit from receiving a great deal of information and support during their D/HH child's transition from EI into the school system.

EI professionals. As universal newborn hearing screening becomes more common across the world (Patel \& Feldman, 2011), children born with hearing loss are increasingly being identified within a few months of birth. Once identified, they are typically referred to EI programs for follow up and support. EI programs that specifically serve $\mathrm{D} / \mathrm{HH}$ children are designed to promote family well-being, positive communicative interactions between child and family members, family engagement in decision making and advocacy for the child, and parent self-efficacy in supporting the child's development (Moeller, Carr, Seaver, Stredler-Brown, \& Holzinger, 2013). This is particularly important for hearing families of $\mathrm{D} / \mathrm{HH}$ children, who are less likely to have smooth and natural communication interactions with their children than are deaf parents (Marschark \& Hauser, 2012).

The qualifications and specific roles of professionals involved in EI vary according to program and provincial or state requirements. However, they are often individuals with training in serving children with developmental delays and/or hearing loss, and in supporting their families. They may include teachers, speech-language pathologists, social workers, or counsellors. In the context of the current study, EI professionals were working with children from age at identification to school entry. The role of EI professionals in the transition to school is crucial. They often act as a liaison between families and schools by providing families with information on school systems and classroom expectations, contacting school district personnel to provide information about 
the incoming student, and facilitating transition meetings (Curle et al., 2016; Rous, Myers, \& Stricklin, 2007).

TODs. TODs typically hold a bachelor's or master's degree in deaf education, and receive specialized training related to educating children with hearing loss. In the context of the current study, TOD refers to a specialized teacher who works with children from Grades $\mathrm{K}-12$. Many TODs are itinerant, serving children and supporting teachers in different classrooms and different schools (Luckner \& Howell, 2002). Because many classroom teachers have little or no experience in teaching children who are $\mathrm{D} / \mathrm{HH}$, collaboration with educators or allied professionals with specialization in deaf education is crucial for a D/HH child's smooth transition to school, as well as for the child's longterm academic performance and integration into the school community. Itinerant teachers work with both students and adults, providing direct services to the student as well as consulting services to the classroom teacher and other adults who provide services and supports to the student (Luckner \& Ayantoye, 2013). The focus of the consultation is on supporting the implementation of classroom accommodations and curricular modifications, to enable students to access academic content and communicate effectively with their teachers and peers (Bullard, 2003). In addition, TODs frequently provide information and support to parents of the children with whom they work. This may include information about hearing loss, educational placement options, amplification systems, and the child's progress at school (Foster \& Cue, 2009). A survey by Luckner and Ayantoye (2013) indicated that itinerant TODs rated consultation with professionals and parents as a highly important aspect of their job, second only to providing direct service to the student. Thus, TODs play an essential role in supporting D/HH children's transition from EI to school.

The body of literature on the transition to school for children with exceptionalities is small, and even less research exists on the transition for children who are D/HH. SassLehrer (2003) reported that families' preparation for the transition from EI to the next stage of schooling was important for the child's positive adjustment. She also noted that supports for families decreased after the child left the EI system. Curle (2015) examined Internet-based information available on the transition to school for $\mathrm{D} / \mathrm{HH}$ children, and found that while most school districts and EI programs have policies or practices in place to smooth the transition from EI to school, few offer information that is easily accessible to families via the Internet, and even fewer have information that is specific to $\mathrm{D} / \mathrm{HH}$ children. Administrator perspectives on the transition to school for $\mathrm{D} / \mathrm{HH}$ children were investigated by Curle et al. (2016). They found that one of the most important facilitators of transition was fluid communication between all stakeholders. However, virtually no documented research has specifically focused on the communication and relationships among the many stakeholders involved.

\section{Theoretical Framework}

The transition to school has often been framed by an ecological perspective (e.g., Bronfenbrenner, 1979; Poon et al., 2016; Rimm-Kaufman \& Pianta, 2000). Such a perspective regards the transition from EI to school as influenced not only by child characteristics, but also by the direct contexts within the child's immediate environment, 
such as family members or teachers and peers, as well as indirect contexts that can affect the child's environment, such as decisions or policies made at school-board or governmental levels. This viewpoint takes into account the importance of relationships among the individuals involved in the child's direct or indirect contexts . By examining the transition process through an ecological systems model, we bring to light the interconnectedness and interplay of the relationships among the child and surrounding individuals, all of whom interact with one another to form a large part of the child's social network (Poon et al., 2016; Rimm-Kaufman \& Pianta, 2000). Thus, it is important to examine the communication that takes place among stakeholders at the level of the child's immediate contexts during the transition from EI and school-most notably, the parents, EI professionals, and TODs - to understand ways in which communication among stakeholders within and across these three social contexts facilitate or impede a smooth transition.

\section{Research Questions}

To address the need for new insights in this field, we adopted two separate but closely related questions as the focus of our research. As D/HH children transition from EI to inclusive kindergarten settings: (a) What are the topics of communication between and among the primary stakeholders? (b) From the perspective of primary stakeholders, what communication-related factors facilitate or impede the transition to school?

\section{Method}

This qualitative study utilized semi-structured group and individual interviews with parents, EI professionals, and TODs to examine the communication among stakeholders. Parents were interviewed twice: once in the fall before their child started school and a second time in the spring. EI professionals and TODs were interviewed once.

\section{Participants and Data Collection}

This study was part of a larger investigation that examined the transition of $\mathrm{D} / \mathrm{HH}$ children from EI to school. Because this study was framed by ecological systems theory, with a focus on the communication among stakeholders in the contexts of home, EI, and school, it was critical to have the input of the stakeholders most integrally involved in the actual transition - parents, EI professionals, and TODs. Itinerant TODs were selected to represent the school system, as they tend to be the professionals in the school system who are most knowledgeable about the impact of hearing loss on a child's development (Foster \& Cue, 2008). Furthermore, they are in regular contact with parents, teachers, administrators, and other service providers for $\mathrm{D} / \mathrm{HH}$ students, and thus have knowledge of the communication that occurs among these stakeholders.

For this particular study, participants were the following: (a) parents of six $\mathrm{D} / \mathrm{HH}$ children moving from EI to inclusive kindergarten classes in public elementary schools in one Canadian province; (b) 11 EI professionals in specialized programs for children who are deaf and hard of hearing and their families; and (c) six itinerant TODs. The participants were questioned about communication both in terms of their own unique 
experiences and in terms of the general practices and policies of the programs with which they were affiliated. The participants in each of the three categories were unaware of the identities of the participants in the other two categories. At the time of data collection, the EI and TOD participants were not serving the children whose parents participated in the study. Ethical approval from the university and school boards was sought and granted. Participants signed a consent form agreeing to take part in the study. All interviews were digitally audio-recorded.

Parents. Participants were selected from a group of 12 parents who took part in the larger study. This larger study was advertised across the province. Six of the 12 families met eligibility criteria for inclusion in the current study, namely, that their children were moving from a specialized early intervention program for $\mathrm{D} / \mathrm{HH}$ children into an inclusive classroom in a public school. Of these six children, three had additional disabilities - one with deaf-blindness and health impairment and two with autism spectrum disorder. Seven parents - five mothers and one couple (mother and father) - participated in the individual interviews. All parents were hearing. All interviews were conducted in English, with five sets conducted face to face; one mother was interviewed by telephone due to distance. Parents were interviewed twice: first in late summer or very early fall, just before their child started kindergarten, and then again at the end of the school year. These interviews (12 in total) were semi-structured and explored parent perceptions and experiences with both EI and school personnel pre- and post-transition. Interviews were conducted by the first and sixth authors, both doctoral students at the time data was collected, with a background in deaf education (one was a speech-language pathologist and the other a TOD). The interviewers had not met the participants prior to the interviews.

Table 1.

Demographic Information of Parent Participants

\begin{tabular}{cllcl}
\hline Parents & Income & Maternal education & $\begin{array}{c}\text { Language(s) } \\
\text { in Addition to } \\
\text { English? }\end{array}$ & Community \\
\hline 1 & Middle & 2-yr college program & No & Suburban \\
2 & High & 4-yr university degree & No & Suburban \\
3 & Middle & High school & No & Suburban \\
4 & Low & 2-yr college program & Yes & Urban \\
5 & Not reported & University courses & No & Urban \\
6,7 & Low & 4-yr university degree & Yes & Suburban \\
\hline
\end{tabular}

In the first interview, demographic data were collected from the parents, along with information about their child's hearing loss. As shown in Table 1, parents represented a range of demographics, particularly in terms of family income, level of maternal education, and languages used in the home. Parents were asked about the EI programs with which they and their child had been involved, as well as the preparation for the transition they had received from the EI program and school. In the post-transition interview, parents were asked to describe their and their child's experiences during the transition to school, as well as what had helped and what had hindered the transition. In 
both pre- and post-transition interviews, parents were asked about the individuals connected with EI and school with whom they had communicated during the transition.

EI professionals. In the Canadian province where this study took place, three specialized EI programs were providing services to children who were $\mathrm{D} / \mathrm{HH}$ and their families from the time hearing loss was identified until school entry, around the age of five years. These program centres were located in the same metropolitan area, but they collectively served children and families throughout the province. The communication approaches and philosophies used among the three EI programs differed, and were described by the respective programs as including Listening and Spoken Language (in which children's listening and speech are emphasized as the primary means of communication), American Sign Language (with an emphasis on involving the family in learning the language and culture of the Deaf community), and Total Communication (in which a combination of spoken language, sign language, and/or visual aids are used, depending on the needs of the child). The researchers asked each program to designate the professionals who were responsible for oversight of the transition process. In the case of one program, the identified professional was a social worker who provided family support. In another program, it was a TOD and the family support worker. In the third program, it was a group of eight TODs and teacher assistants, all of whom were involved in the transition process in various capacities and thus participated in one group interview. All participants were female. The years of experience in EI among participants is shown in Table 2.

Thus, there were three interviews in total, one for each EI program, with a total of 11 EI professionals involved. Interviews were conducted by the second author, a professor in deaf education with extensive experience in EI. Interviews were semi-structured, and followed the same format and order of questions. Participants were asked to describe their roles, practices, and priorities during the transition process, as well as their communication with other stakeholders (parents and educational professionals in school districts).

Table 2.

EI and Teacher Participants

\begin{tabular}{llll}
\hline \multicolumn{1}{c}{ Program } & \multicolumn{1}{c}{ Interview } & \multicolumn{1}{c}{ Participants } & \multicolumn{1}{c}{ Years' experience } \\
\hline EI-LSL & Group & 8 TODs and TAs & $<5$ to $>25$ \\
EI-TC & Group & TOD and family support worker & $20-25$ and 5-10 \\
EI-ASL & Individual & Social worker & $0-5$ \\
School & Group & Itinerant TODs & $<5$ to $>25$ \\
School & Individual & Itinerant TOD & $10-15$ \\
School & Individual & Itinerant TOD & $20-25$ \\
\hline
\end{tabular}

$\mathrm{ASL}=$ American Sign Language; $\mathrm{EI}=$ early intervention; $\mathrm{LSL}=$ listening and spoken language; $\mathrm{TA}=$ teacher assistant; $\mathrm{TC}=$ total communication; $\mathrm{TOD}=$ teacher of the deaf

TODs. This particular set of interviews represented the views of itinerant TODs who served $\mathrm{D} / \mathrm{HH}$ students placed in inclusive public school classrooms. Teachers were recruited online through a listserv for TODs in that province, with an invitation to 
participate in a group interview. Three TODs were interviewed face to face in a group interview at an annual teachers' convention. In addition, two TODs who were not able to join the group interview due to schedule conflicts asked to be interviewed individually by telephone. Thus, there were a total of three interviews (one group and two individual) that included six TODs. All teachers were female with master's degrees in deaf education. All interviews were semi-structured and followed the same format, with the same questions asked in the same order. We acknowledge that information gathered in group interviews may possibly be influenced by peer input. However, we note that the predominant themes emerging within the EI and TOD interviews were similar, regardless of whether they were gathered from individual or group interviews.

The TOD interviews were conducted by the sixth author, a doctoral student and experienced itinerant TOD. Participants were asked to describe their roles, practices, and priorities prior to and after the child's entry into the school system, and their communication with the other stakeholders (parents and EI).

\section{Data Analysis}

Qualitative content analysis of the data was conducted using word processing and spreadsheet software, with coding and analysis discussed with the research team to ensure methodological rigour. The analysis was inductive and iterative. Following the guidelines outlined by Braun and Clarke (2006), the first and sixth authors electronically transcribed the data. The first author read and reread the data and noted initial ideas. Noteworthy features in the data were systematically coded and collated. As code families emerged, a thematic map of the analysis was generated to examine themes in the context of the entire data set. Analysis was continued to refine the specifics of the themes and develop clear labels and definitions for each theme. Guided by the framework of ecological systems theory, the analytical process centered on communication and relationships among the key stakeholders surrounding the child.

Lincoln and Guba (1985) recommended using four criteria for examining the trustworthiness of a qualitative study: (a) credibility, (b) transferability, (c) dependability, and (d) confirmability. Credibility for this study was addressed through prolonged engagement with the data, triangulation through comparison of multiple data sources from three different roles in the transition process (i.e., parents, EI professionals, and teachers) and peer debriefing. Situating the study through the framework of ecological systems theory, as well as linking the current findings to previous research on the transition to school for children with special needs, addresses transferability, or judgment about how well the findings can transfer to a similar population or situation. Dependability addresses the notion of replicability, taking into consideration factors of instability or design-induced changes. This was addressed by describing the method in detail. Finally, confirmability, or the degree to which the results can be confirmed by others, was addressed by keeping an audit trail of the original data, as well as through discussion of method and peer review of the themes and subthemes with the research team over time.

An important factor in assessing trustworthiness in qualitative research is the relationship between the interviewer and the participants (Rooney, 2005). In the current 
study, the interviewers were known to the TOD and EI participants professionally. The interviewers were well positioned to ask relevant and probing questions; the participants appeared comfortable, and at times loquacious, in sharing information. On the other hand, we acknowledge that there was also potential for a threat to validity, in that the participants might possibly have provided responses they thought were expected. However, as shown in Table 2, the EI and teacher participants overall were highly experienced, and it is unlikely that they would have been affected in this way.

\section{Results}

This section presents a description of the themes that emerged regarding communication between each participant group - parents, EI professionals, and TODsalong with the topics that each group raised and discussed. It also describes the apparent effects of these topics in facilitating or impeding the transition.

\section{Communication Between Parents and EI Professionals}

Parents to EI professionals. Overall, the communication between parents and early interventionists was largely one way; that is, from EI to parents. Parents spoke about the information they received from their EI programs via face-to-face conversations, email, or phone calls, rather than the topics they themselves raised or the questions they asked their EI professionals. As they moved through the transition, parents kept their EI professional updated about the child's transition process, such as contact with school personnel, scheduled transition meetings, or visits to the school. None of the parents reported that there was any information that they wanted from their EI program but did not receive. It seems that the EI programs anticipated what information the parents would need. As one parent described, "I didn't need to ask [the EI program questions]. Luckily, the information that was given to me was enough for me to do the transition."

Parents spoke positively about the quick responses they received from the EI professionals with regard to their questions. Parents also valued the trusting relationship they had with their EI programs: Even after her child entered the school system, one mother described how she continued to stay in touch with her child's EI program, telephoning them if she had questions about supports or resources. She said, "It's not like I'm calling a service provider. It's like I'm calling friends," indicating that a close, trusting relationship had been developed between the parent and EI professionals. This relationship seemed to facilitate the transition from EI to school for their child. No parent reported any hindrances to their child's transition to school that were connected to their communication with their EI professionals.

EI professionals to parents. Overall, topics directed from EI professionals to parents about the transition focused on information provision and development of parent advocacy skills. Topics included the school entry process, information about the school system, amplification technology, and parent and student rights in special education. This information was delivered not only through face-to-face conversation during EI sessions, but also through formal parent meetings and workshops (including online access in the case of one EI program) to provide education on the transition process and the school system. EI professionals guided parents through the lists of tasks they needed to complete 
prior to school entry, such as contacting the school district and registering the child for school. EI professionals also provided information about what to expect in the school system by describing kindergarten in terms of class size, academic learning, and social expectations. Additional topics of communication with parents by EI agencies included impact of hearing loss in the classroom, managing audiological equipment, teaching advocacy skills for parents and children, and classroom strategies that support learning for $\mathrm{D} / \mathrm{HH}$ students.

Parents reported that receiving a thorough amount of information and resources from their EI program was helpful in guiding them through the process of the child's transition to kindergarten. As described by one parent:

We had a "ginormous" binder of resources, and a [kindergarten checklist] booklet. "Okay, your child is going into kindergarten and this is what you need to start. You need to get them registered, these are the people you need to contact." You know, it's just all of that kind of stuff. Otherwise, you're sort of a little bit lost — where do I begin?

The EI professionals indicated that at times, the parents demonstrated stress or anxiety when seeking information about the transition. At those times, the EIs provided both emotional support and information to quell parents' fears. As one EI professional described, "I think our job is to take the fear away and try to give them these things that we know. It doesn't have to be an overwhelming process."

The EI professionals felt that providing information to parents about the school system that their child was entering was important preparation, empowering them to advocate effectively for their child:

What we're doing by providing information to families is empowering them. And then it's really up to them. This is where we have to step back and just let them do the research for themselves for their particular child. And that happens, and that's what's exciting.

Only one family reported not receiving information about the school system from their EI program, which they felt hindered their child's transition to school. However, they acknowledged that they did not have the time to attend the meetings and trainings about the transition to school that were provided by their EI centre.

\section{Communication Between EI Professionals and TODs}

EI professionals to TODs. Most of the communication from professionals in EI programs to TODs in schools occurred through phone calls or emails in the early part of the transition process, i.e., prior to the child's school entry; and the majority of the topics related to informing the district about the incoming child. EI providers contacted school district personnel - the assigned TOD or the administrative representative of the school system - to inform them that the child would be attending their district, to provide information about the child's current skills, and to invite the TOD to meet the family and observe the child in the preschool or home setting. EI professionals also communicated recommendations for services and accommodations that they thought the child would need in the school system. 
The TODs reported that receiving written reports about the child was helpful, particularly information about the nature and severity of the child's hearing loss, so that the teacher and school district could prepare for needed accommodations, such as ordering amplification equipment or hiring a sign language interpreter. The EI professionals also considered the observation in the EI program and meeting with the receiving TOD or school district personnel to be highly important for the transition process. For example, one EI professional described the importance of having the TOD observe the child interacting in an environment where sign language was used:

I connect with the [TODs] and invite them to come to our preschool to meet the child and the parents, especially because children who come from our program, regardless of their level of hearing and their spoken language skills, they still are signing kids to some extent, so I want to make sure that the teachers see them in a signing environment to get an idea of that need.

However, the provision of information across government systems (i.e., from EI to school) was not always automatic or guaranteed. Additionally, several TODs reported that EI programs were inconsistent in alerting them to incoming students, stating that they received information more often from the child's community audiologist than from the EI program. A lack of information about the child from the EI program to the school system was regarded as a hindrance to the transition.

TODs to EI professionals. The participants in this study reported little communication from TODs to professionals in EI programs. No TOD reported initiating communication to the EI programs, either to inquire about incoming children or to notify EI programs of their transition process. The EI professionals indicated that this hindered their knowledge of transition practices and key contacts among school districts:

Every year, with certain districts, the process shifts a little bit. And you think that you know it, and then you go, okay, well, that's a little bit different than last year. So, we're never quite sure what's happening in the districts.

The lack of a routine communication pathway from the school to the EI system interfered with EIs having clear, accurate, and current knowledge about school district programs and policies. This is important, given the role that EI programs play in providing information about the transition process to parents in their programs.

\section{Communication Between Parents and School Personnel}

Parents to school personnel. As might be expected, the majority of communication initiated by parents prior to their child's school entry was with school personnel (administrators, office managers, and TOD or classroom teacher) through face-to-face meetings, both formal (such as a transition meeting) and informal. At this point, parents provided schools with information on their child's health, hearing status, and physical needs; inquired about teacher assignment; and made requests for accommodations and services. After the child started school and time progressed, parents increasingly communicated with their child's direct providers, namely the classroom teacher or TOD. Parents provided updates on the child's health, hearing status, and mood, and asked for frequent updates on the child's progress. 
Overall, parents strongly preferred face-to-face communication with their child's teachers. For example, one mother adjusted her work schedule so that she could check in with teachers as she dropped off her daughter at school in the morning:

I was lucky that most of the year I wasn't working, so I could go to school, and I could [talk with the teachers]... Now, I start [my job] at ten o'clock instead of nine. So I can drop kids off and I still have time to talk.

For parents who were unable to see teachers on a daily basis, effective communication was achieved through email or a home-school communication notebook. According to the parents, frequent communication with school personnel helped facilitate the transition by keeping them well informed of the transition process and of how their child was progressing at school, along with details about their child's services and accommodations. Having multiple communication tools also helped, as it ensured that parents were able to reach teachers, even when their schedules did not allow for face-toface interaction. Most parents indicated a preference for daily communication with the school team, as exemplified by one parent:

I like being involved with everything, like knowing what's going on and how he's doing and at least picking up or dropping off and a check in with the teacher and the [educational assistant] to ask, "How was his day today?"

However, despite having regular communication with the school team, some parents were reluctant to share their concerns or complaints, wanting to avoid conflict or fearing negative repercussions for their child. This hindered the transition for parents. For example, one mother was concerned that her daughter was unfairly accused of misbehaviour in the classroom:

I felt like I was going to say something to the teacher, but I bit my tongue because I don't want her to be singled out because, "Your mom is mean to me," (laugh), you know? Like, when you have a battle, you have to find the right battle to choose, right?

This reluctance to express some concerns may indicate that a close, trusting relationship had not yet been developed between parents and school personnel, in contrast to the relationship parents described having had with the EI program.

School personnel to parents. Prior to school entry, communication from schoolbased professionals to parents was largely informational, and came from a school administrator or TOD. Face-to-face communication was used, including both informal interactions and formal meetings, such as transition meetings, meetings related to individualized educational programs, kindergarten open house, or district-wide orientation meetings for parents of children with special needs. Letters were used as communication tools from the school district to parents, informing them of kindergarten orientation or classroom assignment.

Topics included information about the school building, the schedule, teacher assignment, and what services and accommodations the child would receive. This included information about the acoustics in the classroom, amplification equipment, support staff assignment, classroom teacher assignment, and parent rights and responsibilities. Parents were welcomed to visit or observe a classroom prior to school entry, as described by one TOD: 
We encourage the parents to bring the child to come play on the school playground equipment over the summer, and to come and visit the last week of August with the kindergarten teacher, and that seems to [reduce] that anxiety for the parents.

Once the child was attending school, communication from school personnel to parent came mostly from the classroom teacher and TOD, both of whom provided updates to the parents on the child's academic progress, class participation, and the functioning of the child's listening devices. The TODs were aware of the anxiety that many families felt about the transition to school, and addressed this by initiating communication with them prior to school entry. In one situation described by a TOD, this also provided an opportunity to gather important information about the child from the parent:

I remember calling the parent and in a discussion, finding out [the child] was actually more complex, and had [cerebral palsy] and other things. Even a year later, [the parent] said to me at one point how anxious she was, and she remembered how I was the first person to make contact with her, and just how having that dialogue made her feel much more comfortable that [her child's] needs were going to be accommodated for.

Parents who received limited or no communication from the TOD or other school personnel prior to or during their child's start in school reported this as a barrier to a smooth transition from EI to school, and indicated that they felt frustrated. One parent described the kind of information she wished she could have received prior to her child starting school.

[I would like] a little bit ahead to know what's coming. Like, we don't know how often we are going to get speech [therapy]. And they [the school district administrators] don't know who's going to be the teacher. And we don't know what the schedule is going to be ... like, everything's unknown.

\section{Additional Stakeholder Communication}

Although not part of the original research question, one unanticipated theme that emerged was the importance of parent-to-parent communication. Nearly all parents mentioned communicating with other, more experienced parents of $\mathrm{D} / \mathrm{HH}$ children prior to and during the child's school entry to discuss issues related to transition to school. Parents sought and received advice from other parents, and reported having informal conversations and exchange of information with other parents in EI or school-led workshops or orientations, at school, or through online social media. Having opportunities to meet and interact with parents added to their knowledge and understanding of the transition process, and helped alleviate their anxiety.

\section{Discussion}

This study examined the communication among key stakeholders-namely, parents, EI professionals, and TODs - as young D/HH children transitioned from EI to inclusive kindergarten settings. We examined the topics and means of communication among these stakeholders to determine how these factors appeared to help or hinder the transition to school.

The first research question concerned the topics of communication between the primary stakeholders. The predominant finding was that sharing information about the 
$\mathrm{D} / \mathrm{HH}$ child and the school system that the child would be entering facilitated the transition for all stakeholders involved. The different stakeholders needed different types of information. Prior to the transition, schools needed information on the nature and degree of the child's hearing loss, as well as details about any other special needs that the child had in order to plan the child's individualized educational program. Parents needed information about the services and accommodations the school would provide, including school-based amplification systems, to make sure that the child had access to instruction and appropriate supports. The EI professionals did not seek any information about the child during the transition process; their role was to act as mediator between the child's family and school, providing information to families about the school system and about playing the role of advocate for their child, while at the same time providing information to the school about the child's needs. EI professionals also played an important role in arranging meetings between school personnel and families. The role of mediator is important in guiding families as children transition from early childhood settings to school settings, where the expectations change from supporting child development to focusing on academic achievement. This finding supports previous findings, such as those of Villeneuve and Hutchinson (2012), who reported that parents of children with exceptionalities recognized a need for a key person with knowledge of the school-based special education system to guide them through the transition. In the present study, EI programs served that key role, at least in the early part of the transition process.

Parents' needs for information were sometimes embedded in the context of anxiety or stress. Perhaps because of their emphasis on family-centred care and empowerment of parents, EI professionals were the ones to whom parents seemed most comfortable demonstrating this anxiety. They responded by providing information or support to parents as they deemed appropriate. When the children entered the child-centred school system, all parents in this study reported that their anxiety continued. The TODs were aware of the parents' anxiety and made an effort to reach out to them prior to school entry; however, over the course of the school year, some parents voiced a reluctance to disagree with the school team, fearing damage of the relationship between themselves or their child and the teacher. Previous research indicates that parents feel less a part of the team when they leave the family-centred EI system and enter the child-centred school system (Hanson et al., 2000). Furthermore, the formation of trusting relationships between parents and professionals takes time (Rimm-Kaufman \& Pianta, 2000). Thus, some of the parents continued to rely on the relationship they had with the EI programs, and turned to them for information, resources, and support. Although the EI programs stressed the importance of preparing parents to be advocates, it seems that at times, the parents did not feel empowered enough to voice their concerns or disagreements within the school system.

The second research question concerned how the communication among stakeholders facilitated or hindered the transition. All stakeholders recognized the need for parents to receive a great deal of information about the school system prior to kindergarten entry. In terms of communication between EI programs and school, EI programs initiated communication or provided information to schools about the child's current pre-academic, social, language, and hearing skills, although TODs reported that they did not always receive information about $\mathrm{D} / \mathrm{HH}$ children from EI programs. It is 
noteworthy that there was no mention of school personnel initiating communication with EI programs. During the transition process it appears that among the stakeholders in this study, communication was largely one way, from EI to school or from EI to parent. This is likely because the communication involved information about the child, rather than reciprocal information about the transition process. Thus, EI programs were not always clearly informed about specific school district transition practices. Curle et al. (2016) found that EI programs did not always fully understand school district transition policies, and were at risk for providing misinformation to families. These findings suggest that more reciprocal communication between EI programs and schools about the transition process may better facilitate the transition to school.

Once the child entered the school system, the parents in this study preferred frequent, if not daily, communication from teachers about the child's behaviour, academic progress, and functioning of the amplification equipment. The shift from a family-centred model to the new setting and more child-centred model is often a difficult adjustment for families (Dunst, Boyd, Trivette, \& Hamby, 2002). Many parents of children with exceptionalities feel as if they are outsiders in the school system, as opposed to the EI system (Podvey, Hinojosa, \& Koenig, 2013). Providing parents with frequent updates on their child's academic progress and behaviour seemed to help alleviate some of the parents' anxiety and facilitated a smooth transition to school.

A final finding that emerged from this study is that parents found a source of information and support in other parents of $\mathrm{D} / \mathrm{HH}$ children, through both face-to-face dialogue and through Internet-based social media groups. The EI programs recognized the need for parent-to-parent communication and invited children and families who were already in the school system to meet with parents of children who were beginning the transition from EI to school. The importance of more experienced parent mentoring and support for parents of $\mathrm{D} / \mathrm{HH}$ children has been documented in previous research (Jackson et al., 2008; Narr \& Kemmery, 2014). The current study supports the importance of parent-to-parent support during the transition to school.

\section{Limitations and Directions for Future Research}

Obvious limitations to this study were that it was conducted in one geographic region in Canada and represents the experiences of a small number of participants. However, this study adds to the body of research on the transition to school for children with exceptionalities, particularly children who are $\mathrm{D} / \mathrm{HH}$.

While the current study examined $\mathrm{D} / \mathrm{HH}$ children transitioning from specialized EI programs into inclusive settings, future research should investigate the transition of $\mathrm{D} / \mathrm{HH}$ children who did not participate in specialized EI programs. Also, the transition from EI into specialized settings, such as $\mathrm{D} / \mathrm{HH}$ programs or schools for the deaf, should be investigated, as should the transition to school in other geographical regions, both urban and rural. In addition, as technology continues to evolve, future research could shed light on ways in which technological advances in communication tools can strengthen fluid communication among stakeholders. 
One final limitation is that we did not ask the participants directly about their topics and tools of communication - this information emerged in the context of discussing factors that facilitated or hindered the transition. Future studies could investigate this line of research further by asking participants directly about how and what their communication with one another entailed. Results from such studies have the potential to inform parents, teachers, EI professionals, and administrators of effective ways to manage communication and transition practices, with a view to providing a smooth transition to school for children who are $\mathrm{D} / \mathrm{HH}$.

\section{Implications for Deaf Education}

In conclusion, this paper highlights the importance of communication among stakeholders - particularly parents, EI professionals and TODs - as young children who are $\mathrm{D} / \mathrm{HH}$ transition from the EI system to school. A number of important potential implications could be considered for the field of deaf education. First, school districts should keep EI programs updated on changes in school policies and practices relevant to $\mathrm{D} / \mathrm{HH}$ children entering kindergarten. Second, TODs as well as classroom teachers should be aware of the importance of frequent communication with parents during a $\mathrm{D} / \mathrm{HH}$ child's kindergarten year. Third, parents of $\mathrm{D} / \mathrm{HH}$ children need opportunities to connect with one another for information sharing and emotional support. Fourth, given the likelihood that classroom teachers in integrated settings have limited knowledge and experience about educating $\mathrm{D} / \mathrm{HH}$ children, and the further likelihood that itinerant TODs may not see the child on a daily basis, it is crucial that parents be able to advocate effectively for their child by stating disagreement with practices or treatment that they feel do not support their child. School districts should consider providing conflict resolution training to teachers, and encourage an environment of openness and consideration of parent perspectives.

\section{References}

Braun, V., \& Clarke, V. (2006) Using thematic analysis in psychology. Qualitative Research in Psychology, 3(2), 77-101. doi:10.1191/1478088706qp063oa

Briody, M. F., \& Martone, J. M. (2010). Challenges and considerations when transitioning preschoolers with complex medical histories to kindergarten. Journal of Early Childhood \& Infant Psychology, 6, 117-132. Retrieved from https://www.questia.com/library/p438489 /journal-of-early-childhood-and-infant-psychology

Bronfenbrenner, U. (1979). The ecology of human development: Experiments by nature and design. Cambridge, MA: Harvard University Press.

Bullard, C. (2003). The itinerant teacher's handbook. Hillsboro, OR: Butte Publications.

Curle, D. (2015). An examination of web-based information on the transition to school for children who are deaf or hard of hearing. Deafness \& Education International, 17(2), 63-75. doi:10.1179/1557069X14Y.0000000039

Curle, D., Jamieson, J., Buchanan, M., Poon, B. T., Zaidman-Zait, A., \& Norman, N. (2016). The transition from early intervention to school for children who are deaf or hard of hearing: Administrator perspectives. Journal of Deaf Studies and Deaf Education, 22(1), 131-140. doi:10.1093/deafed/enw067 
Decker, K. B., Vallotton, C. D., \& Johnson, H. A. (2012). Parents' communication decision for children with hearing loss: Sources of information and influence. American Annals of the Deaf, 157(4), 326-339.

Dunst, C. J., Boyd, K., Trivette, C. M., \& Hamby, D. W. (2002). Family-oriented program models and professional help giving practices. Family Relations, 51(3), 221-229. doi:10.1111/j.17413729.2002.00221.x

Fitzpatrick, E., Angus, D., Durieux-Smith, A., Graham, I. D., \& Coyle, D. (2008). Parents' needs following identification of childhood hearing loss. American Journal of Audiology, 17(1), 3849. doi:10.1044/1059-0889(2008/005)

Fitzpatrick, E. M., Jacques, J., \& Neuss, D. (2011). Parental perspectives on decision-making and outcomes in pediatric bilateral cochlear implantation. International Journal of Audiology, 50(10), 679-687. doi:10.3109/14992027.2011.590823

Foster, S., \& Cue, K. (2009). Roles and responsibilities of itinerant teachers of deaf and hard of hearing students. American Annals of the Deaf, 153(5), 435-449. doi:10.1353/aad.0.0068

Gallaudet Research Institute. (2013). Regional and national summary report of data from the 2011-2012 Annual Survey of Deaf and Hard of Hearing Children and Youth. Washington, DC: Author.

Hanson, M. J., Beckman, P. J., Horn, E., Marquart, J., Sandall, S. R., Greig, D., \& Brennan, E. (2000). Entering preschool: Family and professional experiences in this transition process. Journal of Early Intervention, 23(4), 279-293. doi:10.1177/10538151000230040701

Jackson, C. W., Traub, R. J., \& Turnbull, A. P. (2008). Parents' experiences with childhood deafness: Implications for family-centered services. Communication Disorders Quarterly, 29, 82-98. doi: $10.1177 / 1525740108314865$

Jamieson, J. R., Zaidman-Zait, A., \& Poon, B. (2011). Family support needs as perceived by parents of preadolescents and adolescents who are deaf or hard of hearing. Deafness \& Education International, 13(3), 110-130. doi:10.1179/1557069X11Y.0000000005

Janus, M., Lefort, J., Cameron, R., \& Kopechanski, L. (2007). Starting kindergarten: Transition issues for children with special needs. Canadian Journal of Education, 30(3), 628-648. doi: $10.2307 / 20466656$

Kurtzer-White, E., \& Luterman, D. (2003). Families and children with hearing loss: Grief and coping. Mental retardation and developmental disabilities research reviews, 9(4), 232-235. doi:10.1002/mrdd.10085

Lincoln, Y., \& Guba, E. (1985). Naturalistic inquiry. New York, NY: Sage.

Luckner, J. L., \& Ayantoye, C. (2013). Itinerant teachers of students who are deaf or hard of hearing: Practices and preparation. Journal of Deaf Studies and Deaf Education, 18(3), 409-423. doi:10.1093/deafed/ent015

Luckner, J. L., \& Howell, J. (2002). Suggestions for preparing itinerant teachers: A qualitative analysis. American Annals of the Deaf, 147(3), 54-61. doi:10.1353/aad.2012.0210

Marschark, M., \& Hauser, P. (2012). How deaf children learn. New York, NY: Oxford University Press.

McIntyre, L., Eckert, T., Fiese, B., DiGennaro, F., Reed, F., \& Wildenger, L. (2010). Family concerns surrounding kindergarten transition: A comparison of students in special and general education. Early Childhood Education Journal, 38(4), 259-263. doi:10.1007/s10643-010-0416-y

Moeller, M. P., Carr, G., Seaver, L., Stredler-Brown, A., \& Holzinger, D. (2013). Best practices in family-centered early intervention for children who are deaf or hard of hearing: An international consensus statement. Journal of Deaf Studies and Deaf Education, 18(4), 429445. doi:10.1093/deafed/ent034 
Narr, R. F., \& Kemmery, M. (2014). The nature of parent support provided by parent mentors for families with deaf/hard-of-hearing children: Voices from the start. Journal of Deaf Studies and Deaf Education, 20(1), 67-74. doi:10.1093/deafed/enu029

Patel, H., Feldman, M., Canadian Paediatric Society, \& Community Paediatrics Committee. (2011). Universal newborn hearing screening. Paediatric Child Health, 16(5), 301-305. doi:10.1093/pch/16.5.301

Pianta, R., \& Kraft-Sayre, M. (2003). Successful kindergarten transition. Baltimore, MD: Paul H. Brookes.

Podvey, M., Hinojosa, J., \& Koenig, K. (2013). Reconsidering insider status for families during the transition from early intervention to preschool special education. The Journal of Special Education, 46, 211-222. doi:10.1177/1088357614532497

Poon, B., Jamieson, J., Zaidman-Zait, A., Curle, D., Norman, N., \& Simmons, N. (2016). The transition from early intervention to school for deaf and hard-of-hearing children. In M. Marschark, V. Lampropoulou, \& E. Skordilis (Eds.), Diversity in deaf education (pp. 49-75). New York, NY: Oxford University Press.

Poon, B. T., \& Zaidman-Zait, A. (2014). Social support for parents of deaf children: Moving toward contextualized understanding. Journal of Deaf Studies and Deaf Education, 19(2), 176-188. doi:10.1093/deafed/ent041

Qi, S., \& Mitchell, R. E. (2012). Large scale academic testing of deaf and hard-of-hearing students: Past, present, and future. Journal of Deaf Studies and Deaf Education, 17(1), 1-18. doi:10.1093/deafed/enr028

Rimm-Kaufman, S. E., \& Pianta, R. C. (2000). An ecological perspective on children's transition to kindergarten: A theoretical framework to guide empirical research. Journal of Applied Developmental Psychology, 21(5), 491-511. doi:10.1016/S0193-3973(00)00051-4

Rooney, P. (2005, May). Researching from the inside-Does it compromise validity? [Electronic version]. Level 3, 1-19. Retrieved from http://level3.dit.ie/html/issue3_list.html

Rous, B., Myers, C. T., \& Stricklin, S. B. (2007). Strategies for supporting transitions of young children with special needs and their families. Journal of Early Intervention, 30(1), 1-18. $10.1177 / 105381510703000102$

Sass-Lehrer, M. (2003). Programs and services for deaf and hard of hearing children and their families. In B. Bodner-Johnson \& M. Sass-Lehrer, (Eds.), The young deaf or hard of hearing child: A family-centered approach to early intervention (pp. 153-180). Baltimore, MD: Paul H. Brookes.

Spencer, P., \& Marschark, M. (2009). Deaf children: Education from research to practice. New York, NY: Oxford University Press.

Welchons, L. W., \& McIntyre, L. L. (2015). The transition to kindergarten for children with and without disabilities: An investigation of parent and teacher concerns and involvement. Topics in Early Childhood Special Education, 35(1), 52-62. doi:10.1177/0271121414523141

\section{Authors' Note}

Correspondence concerning this article should be addressed to: Deirdre Curle, Center for Childhood Deafness \& Hearing Loss, 611 Grand Blvd., Vancouver, WA, 98661-4918. Email: deirdre.curle@gmail.com 